\title{
The Reciprocal and Correlative Relationship Between Learning Culture and Online Education: A Case from Saudi Arabia
}

\section{Abstract}

The purpose of this paper is to build on the insights of educators regarding the relationship between culture and online learning. More specifically, this paper aims to explore the ways in which students' culture of learning is changing as a result of the introduction of various modes of online learning. It also aims to explore the ways in which culture and cultural values affect the application and success of online-learning strategies. Particular attention is directed to learners' perceptions of the advantages and disadvantages of online communication. The paper is based on primary data drawn from undergraduate female students' responses regarding how online education is changing their learning culture and how their culture is influencing online education. Sixty-seven undergraduate Saudi female students participated in the survey. The literature in the field of online and distance education is explored to help answer these questions. The participants indicated that online education helped them to challenge some cultural norms, enhance their learning culture, and improve their communication skills.

Keywords: Online education; distance education; cultural implications of online learning; Saudi Arabia online learning; online education and cultural issues; integrative approach 


\section{Introduction}

Challenging traditional, face-to-face methods of teaching and moving towards innovative, student-centered approaches are crucial trends in contemporary education. Online education in particular is emerging as an important feature of higher education in all fields. Over the last decade, educational programs worldwide have begun to employ online learning as an essential part of the delivery of courses and even of entire programs, to the extent that it is now part of the higher education mainstream in many countries. "Students are demanding more courses and programs to be offered online. Yet, in light of the growing population of learners from various cultural backgrounds engaged in online education..." (Wang \& Reeves, 2007, p. 1), there is an urgent need to understand how culture affects online education and, conversely, how online education affects learning culture.

Culture, as defined by Hofstede (2005), is "the collective programming of the mind that distinguishes the members of one group or category of people from others" (p. 4). These differences in programming largely account for differences across cultures. It is clear that cultures and cultural values around the globe are changing in unprecedented ways as a result of the exponential growth of communication-exchange channels, an important aspect of which is the increasing ease of access to online courses, programs, and information. "Learning culture" is a concept that overlaps with "culture" but is also distinct. Learning culture can be defined as the ways in which students perceive their educational materials, their class discussions (whether in-person or virtual), their teachers/professors as knowledge providers or facilitators, and the meaning and purpose of education (as being either a means to a specific objective like a particular career or an end in itself). The culture of learning is currently undergoing a rapid transition worldwide, including in the Middle East. Saudi Arabian students, for example, have begun to participate in this communications exchange and, in consequence, their culture of learning is changing in ways that could not have been anticipated even two or three years ago. These students, both female and male, are now able to access learning resources such as journals, magazines, periodicals, and intercultural communication forums that would not be available to them but for their connection to the Internet. The unprecedented openness to new educational resources and cultural perspectives is leading Saudi Arabia's younger generation to become less traditional and strict in their views. Other Saudi scholars such as Alenezi (2012) and Al Seghayer (2013) have indicated that online learning is opening new opportunities for Saudi students to question traditional assumptions of what learning is. The implications of this process for the Saudi culture as a whole are reinforced by the fact that the youth component of the Saudi population (i.e., those under age 35) currently stands at $65 \%$ of the total.

This paper aims to explore the ways in which Saudi students' culture of learning is changing as a result of the introduction of various modes of online learning. It also aims to explore the ways in which culture and cultural values affect the application and 
success of online-learning strategies. Particular attention is directed to learners' perceptions of the advantages and disadvantages of online communication. This research analysis is based on observations of two groups of Saudi female university students as they began to integrate online-learning systems into their studies. The analysis also draws on the key literature relating to online learning.

This paper submits that online education and culture have a reciprocal and correlative relationship. In this paper I explore how the culture of learning has changed for Saudi students as a result of using online learning and how online learning and teaching, notwithstanding their structural issues and obvious infrastructural weaknesses, have helped students change their perceptions. This paper explores the emergence of online education globally and in Saudi Arabia; issues, controversies, and problems; traditional education as the backdrop to Saudi online learning; and, finally, the findings of an empirical study on the same.

\section{Research Context}

\section{Saudi Education: The Traditional Approach}

Since the advent of public education in Saudi Arabia in the 1960s, the Kingdom has adhered to a traditional educational culture. This system is premised on the transmission of information from the professor or teacher ("the power") to the students ("the empty vessels" / "the disempowered"). Paulo Freire (1970) has developed a similar analogy to describe this approach, which he calls the "banking system of education"; this is an educational approach that resembles "an act of depositing, in which the students are the depositories and the teacher is the depositor" (p. 53; p. 72). The banking system of education is the antithesis of what Freire advocates - an education that announces the importance of dialogue, engagement, and equality, denounces silence, and deplores oppression.

Saudi education continues to manifest many aspects of the banking system. In accordance with Freire's analogy, Saudi professors and teachers do not usually engage in dialogue with students over the course of the learning process but instead they impose information that is often irrelevant to students. Indeed, critics of the Saudi curriculum and pedagogy point out that the Saudi education system does not reflect the experiences of the majority of students and that much of what they learn is largely irrelevant to their lives and careers, especially in the curriculum that was used prior to the implementation of a reformed curriculum in 2009 (Hamdan, 2012, 2013; Almutairi, 2008; Duignan, 2012). On standardized tests, Saudi students are often expected to provide answers that may have little or no connection to their background or context. This is also the situation in most Arab Muslim universities and schools. 
In my experience, as both a student and a teacher in the Saudi education system, critical thinking is not emphasized. By critical thinking, I refer to two elements. The first element is gaining a deeper understanding of issues and problems and the second element is examining and evaluating arguments from multiple points of view (McPeck, 1981). My perspective is that students continue to learn from a very young age that knowledge and "truth" are fixed, that all claims to truth are either black or white, and that what is taught in school or university is therefore unquestionable. While the roots of this phenomenon fall outside the scope of this paper, it should be acknowledged that the Saudi approach of focusing Islamic school curricula on only one school of Islamic thought may train students to think rigidly and to exclude diversity. If on the other hand students were exposed to a range of Islamic perspectives, they would have an early opportunity to expand their critical-thinking skills. The school of Islamic thought that is predominant in Saudi Arabia is based on Hanbali, which is named after Ahmed bin Hanbal who was a Muslim scholar and a great Imam of Fiqh (Islamic jurisprudence). Hanbal helped to provide one of the main interpretations of the main texts, the Holy Quran and Sunna. Quite apart from the authority of Hanbal's scholarship, the salient issue is the gap between theory and practice. The general books, media, and focus of society from the early 1980s to less than a decade ago promoted only the Hanbali interpretation of Islam and this contributed to the exclusion of a diversity of perspectives. This narrow approach does not represent the essence of the Islamic faith, especially given the extensive evidence of diversity in the Quranic texts and in the Prophet's (Peace Be Upon Him) narrations. This narrowness is not only true in Islamic societies but also in the West when on the one hand the law supports multiculturalism while on the other hand many right-wing voices call for exclusion of diversity.

Despite the continuing dominance of rote memorization and passive learning in the Saudi education system, there are also many reasons for optimism. There is great enthusiasm surrounding the emphasis of King Abdullah Bin Abdulaziz on education as a tool of empowerment. This emphasis is exemplified by a drive to achieve a position of scientific leadership in the Arab world, by participation in international scientific competitions, and by the establishment of the King Abdulaziz and His Companions Foundation for the Gifted (Mawhiba), which is a new centre to promote talent and innovation. A reformed curriculum is in the process of being implemented in schools and many innovative measures are being considered and implemented both by the Ministry of Education (which oversees K-12) and by the Ministry of Higher Education or MoHE (which oversees all colleges, universities, and other post-secondary institutions). One of these innovative measures is the promotion of online learning, which is opening up teachers and students to look beyond the strictures of the banking system of education.

\section{Global Emergence of Online Education}

Although many observers initially considered online learning to pose a threat to the concept of classroom-based instruction and its delivery of experiences, it is today 
generally considered to be a complement to classroom instruction. Online education is increasingly being acknowledged by educators as encouraging students to take greater responsibility for their own learning and as “..offering more self-paced learning alternatives and providing a richer interactive learning environment than learning from text" (Newton, Hase, \& Ellis, 2002, p. 162). Wang and Reeves (2007) note that "College and university students in the USA increasingly view online components of their courses as commonplace as textbooks and other traditional resources" (p. 2). Online education and embedded online communication in higher education courses and programs are no longer considered luxuries or mere supplements to learning but, rather, are treated as integral parts of higher education in many parts of the world. This is true not only of North American and European institutions but also of institutions in Saudi Arabia. These trends coupled with the emergence of the global knowledge-oriented economy have not only encouraged governments to provide the infrastructure for web-based instruction but have also necessitated a significant increase of investment in internet technologies to increase access to educational resources.

\section{Online Education in Saudi Arabia.}

Online learning, including distance education by online means, has received increasing attention among Saudi educators as a way of increasing the accessibility of higher education. This type of instruction offers access to many students who aspire to study at the university level but live in remote areas or are working to earn income and therefore are unable to physically attend school. Distance education is an aspect of online education that continues to offer great untapped potential. As Al-Khalifa (2009) remarked, Saudi Arabia "has been slower than many nations to move into distance education and that it has a very short history of using printed, electronic, or broadcast means for students who are not physically on site" (para. 1).

The need to expand access to higher education is one of the main factors driving the ongoing growth of online learning in the Kingdom. In addition to the desire to make university education available to students who are located in rural areas or who are currently employed, there are powerful demographic forces at work. According to the latest national statistics, by 2009 Saudi Arabia's youth population had reached 65\% of the entire population. Many high-school graduates were unable to find places at the national universities and approximately 100,000 are currently studying abroad on scholarships at higher education institutions in such countries as the United States, the United Kingdom, and Canada. Online learning offers the prospect of expanding the total number of students who can be enrolled in Saudi universities without actually requiring increases in the physical capacity of the universities and associated facilities. Public and private higher education institutions in Saudi Arabia cannot accommodate the increasing number of high-school graduates who wish to obtain a university degree and thus it is paramount that online learning and certification become part of the structure of higher education. Another factor encouraging the implementation of online learning is the visual learning style of many Saudi students. Online approaches, which of course 
incorporate visual learning, can therefore enhance the traditional and relatively passive approaches to education. This new mode of teaching offers great potential to make students more self-directed and engaged.

The Saudi Ministry of Higher Education has begun to acknowledge the need to adopt online technologies in order to offer opportunities to the increasing numbers of students graduating from high school. According to Tony Bates (2009), a consultant who runs many e-learning workshops and provides e-learning training across the region, some of the more forward-thinking leaders of Saudi education have been exploring online education over the course of the last decade:

King Fahd University in Dhahran has been working closely with UBC in Canada since 2003, with staff from King Fahd University visiting UBC for workshops a few times over this period. The use of e-learning at King Fahd University for Oil and Petroleum, for instance, had become widespread, both to support classroom teaching and in a hybrid mode, with a mix of reduced classroom time and online learning. (para. 3)

These workshops have been part of the plan of the Ministry of Higher Education to study the feasibility of offering online education blended and integrated with traditional methods of course delivery.

As of 2013, many Saudi universities were well advanced in integrating online learning into almost every undergraduate program. Major universities are currently implementing or have already fully implemented web-based instruction through Web CT or Blackboard as a companion to all their classroom study programs. According to Mirza (n.d.),

MoHE has just recently established a national centre for e-learning and distance learning which aims to support in the creation of electronic educational material, and provide an electronic venue for faculty members of any local university to utilize in creating e-courses through its own Learning Management System. (p. 4)

There are currently large numbers of undergraduate students enrolled in online degrees in all major Saudi universities. Some students are earning bachelor's degrees in business administration, Arabic language, Islamic studies, sociology, and history that are exclusively online. In 2011 a new electronic university was established with three colleges and an enrolment of more than 20,000 students across the Kingdom (ses.edu.sa). Nevertheless, there remains considerable reluctance among some stakeholders to introduce entirely online degree programs, including among leaders within the Saudi Ministry of Higher Education. In addition, the MoHE remains 
unprepared to accept or qualify anyone with an online qualification from any foreign institution, even from such renowned universities as MIT, Harvard, and Stanford which offer some online programs. These concerns stem from the fact that the very nature of online program delivery can raise doubts about whether students are in fact submitting their own work and, by implication, about the fairness of the evaluation of students' performance.

\section{Literature Review}

\section{Advantages of Online Education}

The literature concerning online learning has greatly expanded over the last decade. Studies have indicated that online learning enables institutions and/or instructors to reach new learners at a distance, increase convenience, and expand educational opportunities (Bourne, McMaster, Rieger, \& Campbell, 1997; Hara \& Kling, 2000; Hill, 2002; Hofmann, 2002; Owston, 1997; Rourke, 2001; Schrum, 2000; Song et al., 2004). Studies have typically emphasized the key characteristics of successful online learners; Ohara (2004) has summarized some of the main work of researchers in this area. Ohara's primary finding was that online learners - out of many characteristics such as level of engagement, the ability to deal with uncertainty, and the willingness to try new things - have most notably displayed internal locus of control, which is the ability to exercise a degree of personal, internally driven control over key life decisions (Cooper, 1990; Altman \&Arambasich, 1982; Parker, 1999 as cited in Ohara, 2004, p. 51).

Among the many advantages cited by researchers with regard to offering online learning opportunities to students are "[v]alidity, relevance, ease of editing and updating, use of visuals and minimal text and the potential for interaction both with the content and with peers or facilitators" (Newton, Hase, \& Ellis, 2002, p. 163). To these advantages Ohara (2004) added the proposition that

...student satisfaction - as identified through comments after the class ends - is generally higher for those students who have immersed themselves in the program by participating in scheduled and informal online chats and maintaining a steady stream of comments in discussion forums. (p. 51) 


\section{Disadvantages, Issues, and Controversies}

Some researchers have argued that "technology is culturally, morally, and politically neutral - that it provides tools independent of local value systems which can be used impartially to support quite different kinds of lifestyle" (Pacey, 1983, p. 2). However, a strong case can be made that this is a misconception, particularly of the Western world, towards what are typically identified as "developing" countries (formerly known as "Third World" countries). Part of the problem is that the West to a great extent has adopted a set of beliefs or a world view whereby, as Tony J ackson says, "the Third World is portrayed as a vast refugee camp, with hungry people lining up for food from the global food aid soup kitchen" (Pacey, 1983, p. 57). Yet, "this view is false" (Pacey, 1983, p. 57), not least because there are many countries in the Eastern part of the world such as China and India that are no less technologically advanced than those of the Western world. Technological advancement is not neutral because it differentiates between powerful and less powerful nations in terms of access to sophisticated technology in such a way that the success of some countries often comes at the expense of other countries.

Some studies have indicated that back-and-forth interaction with other individuals is one of the keys to online success - more so than in traditional settings such as the lecture hall or the classroom which generally allow only for one-way communication from the professor or teacher to the student (Picciano, 2002 as cited in Kim, Liu, \& Bonk, 2005). However, Picciano (2002) did not identify the specific elements of online learning that enabled students to be successful nor did he outline the parameters governing their success. Kim, Lei, and Bonk (2005) argued that, especially in asynchronous conferencing, online learning fosters rich interactions and in-depth thinking because it provides participants with a greater amount of time in which to process other participants' statements and to formulate their responses. The study by Kim, Liu, and Bonk (2005), as well as a few others like that of Benbunan-Fich and Hiltz (1999), suggest that online interaction helps improve students' skills in the sense that they are able to provide more detailed answers to cases and problems by means of online discussion; however, these studies offer no details regarding the skills that were improved and the specific ways in which online learning helped students to build their

social-interaction skills and other skills. Finally, Ohara (2004) indicated that some students

...doubt the technology and their ability to use it properly and require reassurance from their instructor before they begin to trust the technology. Some students never learn to trust and never reduce their uncertainty with the technology. (p. 51) 


\section{Cultural Impact}

Despite the growth in literature concerning online learning, there has been little emphasis on the ways in which online learning and the unprecedented openness of online communication have been changing learning cultures around the world in general and that of Saudi Arabia in particular. One of the few examples is Moon (1999), who suggests that "open communication in online forums is offering examination of beliefs [sic] systems and cultural assumptions" (as cited in Cameron \& Limberger, 2004, p. 434).

Similarly, there has been little emphasis on the ways in which culture affects the application and success of online learning. Indeed, "Although few would disagree that cultural factors are important in theory, there is surprisingly little published literature concerning the cultural aspects of online learning and teaching, and there are even fewer research-based studies on the subject" (Gunwarandena, Wilson, \& Nolla, 2003 as cited in Wang \& Reeves, 2007, p. 2). There remain many pertinent aspects of learning culture that have not yet been discussed in the higher education literature. For example, inadequate attention has been thus far accorded to the effects of online learning on such aspects of students' learning culture as locus of control, empowerment, and the inherent tensions between individualism and collectivism and between autonomy and agency.

An especially insightful study by Tapanes, Glenn, Smith, James, and White (2009) focused on the cultural diversity of online learning and on the perceived effects of conflict levels of individualism, collectivism, and tolerance of ambiguity. This article, like many others, highlighted the differences among people from a variety of cultural backgrounds in terms of the extent to which they demonstrated individualism, collectivism, and intolerance for ambiguity. However, the study did not discuss the extent to which - if at all - exposure to online education contributed to enhancing students' actual learning. Another study by Pattison (2003) explored how students from diverse cultural backgrounds who were drawn together in a program to train counselors reflected on their experience as online learners and in particular in online discussions. Pattison's approach is based on an individual-centered orientation that makes the individual the primary user and beneficiary of online-learning technology.

The lack of research into how online communication and other forms of technological advancement are influencing Eastern countries, their peoples, and their cultures is in part a reflection of the lack of advancement in the field of online learning in many of these countries. This is why there seems to be a near absence of understanding of the ways in which online learning is influencing different countries of the Eastern world. This absence is particularly acute given the fact that many countries are trying to adapt to new methods of learning. This type of understanding is not a luxury but a necessity as most societies around the world become increasingly knowledge-based. 


\section{Theoretical Framework for the Study}

\section{Cultures}

Important research about cultures has differentiated between high-context cultures and low-context cultures. The definition of culture articulated by Hofstede and Hofstede (2010) is that "every person carries within him or herself patterns of thinking and feeling and potential acting that were learned throughout their lifetime" (p. 2). They defined high-context cultures in which direct communication is minimal because most of the information is in the immediate physical and social environment and little is encoded. This type of communication is common in collectivist cultures such as that of Saudi Arabia. This reflects the great significance of body language in general and of gestures in particular. A low-context culture, on the other hand, is "one in which the mass of information is vested in the explicit code which is typical of individualist cultures" (Hofstede \& Hofstede, 2010, p. 89). When information is embedded in an explicit code, few if any contextual details or clues are provided to the receiver regarding the message and the meaning is almost entirely enveloped within and understood through the actual words that are communicated. According to Gupta (2010),

High context cultures are ones in which people tend to be indirect and formal communicators. People from low context cultures tend to be direct and informal communicators. Groups that have high context communication styles combine verbal and nonverbal messages to convey the entire meaning. A listener must read between the lines and add nonverbal nuances to fully understand the message. (para. 9)

Similarly, according to Borisoff and Victor (2007), "In high context cultures, members rely heavily on inferred meaning while in low context cultures people strive hard to find a literal meaning" (as cited in Corvette, 2007, p. 104). Borisoff and Victor (1989) also found that

...high-context cultures include the Chinese, Korean, Japanese, Vietnamese, Arabian and Greek cultures as well as, to a lesser extent, the Spanish and Italian cultures (as cited in Corvette, 2007, p. 103). Saudi Arabia would be classified as having a high-context culture whereby context is of great significance to the discernment of meaning. (p. 23)

In online communication, context is not able to play as great a role as it plays in many other forms of interaction. Given the fact that online communication is effected by 
written means, it follows that the study participants were not able to offer any subtle, non-verbal cues through tone of voice and body language, which are critical aspects of face-to-face communication in the Saudi culture. When learners engage in online communication, the role of context is far less significant than in conventional communication and this, in turn, affects their locus of control. Saudi female students the group from which the subjects of this study were drawn - usually display external locus of control and this impairs their ability to independently make major decisions in their lives. In high-context cultures such as that of Saudi Arabia, people are especially willing to use social power to accomplish their goals. Given the fact that the use of the Internet impairs the traditional, non-verbal means of communicating social power, it follows that Saudi students' engagement in online learning is teaching them to become more independent and to take charge of their own decisions.

\section{Empowerment}

In this study, I specifically acknowledge the fact that learning is both a personal and a social endeavour. According to Piaget (2000) and the constructivist theorists, learning is not a product transmitted from the more knowledgeable party (the teacher/instructor) to the less knowledgeable party (the students). Rather, from a constructivist point of view, learning is achieved in an environment in which the student is at the centre of the learning process and the role of the teacher is to act as a learning facilitator. Online learning provides an opportunity whereby students can construct their own understanding and their own knowledge with less pressure from teachers, peers, and family members. For instance, the Internet makes it much easier for students to conduct research and to learn about perspectives that may be quite different from those presented by the professor/teacher and in the official textbook(s). Furthermore, online education is geared to the fact that learning is a social endeavour as well as to the collectivist character of the Saudi culture. According to Vygotsky (1992), learning to a great extent occurs as a result of personal interaction, not just between instructors and students, but equally importantly [good] among students themselves. I argue that in Saudi Arabia students learn best when they are immersed in an educational context that promotes interaction among peers. "Social constructivism is therefore a theory of learning empowerment within which students are conferred agency in the learning process, higher levels of responsibility over learning and choices about what, where and how to learn" (Renner, 2006, p. 4). Renner (2006) continues by stating that "Learning is both personal and social. It is personal to the extent that individual students must construct their own understandings. These understandings are subsequently regulated and tested through social interactions" (p. 4). 


\section{Methodology}

The primary method of gathering data for this study was a survey. There were 12 survey questions (Appendix B) and 100 copies were sent out to students. Participation was voluntary as indicated in the letter of information (Appendix A). Students were reminded that they could withdraw from the study at any time without any penalties and they were asked to bring the written answers to the following class and submit them to the teaching assistant.

\section{Validity of the Questionnaire}

The validity of the questionnaire was explored through the use of experts: a professor emeritus whose specialty is curriculum and online learning, and two external educators. The professor was also asked to judge the clarity of the wording and the appropriateness of each item and its relevance to the main research questions being asked. The experts were asked to consider the following questions:

1. What do you think the questionnaire measures? Does it represent assessment principles and the content of the course?

2. Is it appropriate for the sample/ population?

3. Is the questionnaire comprehensive enough to collect the information needed to address the purpose and goals of the study?

The professor's feedback and directives were used to further refine the questionnaire. The validity of the questions was also checked by inviting three educators whose backgrounds are in curriculum and online learning to provide feedback and to explain the extent to which the questionnaire addressed the main research foci. Some parts of the questionnaire were changed in accordance with the feedback from the referees.

The reliability of the questionnaire was explored through a pilot study involving 30 students who were not part of the larger study. The responses collected from the pilot study were analyzed to determine the level of consistency between the stated advantages and disadvantages on the one hand and the stated preferences on the other hand. There appeared to be internal consistency among these respondents' weighted advantagesdisadvantages, their preferred assignment, and the justification for their choice. This result was taken as evidence of the questionnaire's reliability (internal consistency) in this low-risk study.

\section{The Participants}

The study participants were all female first-year undergraduate students at two Saudi universities in which the medium of instruction is English. Because of the gender segregation of the Saudi education system - males are taught only by males, whereas women may be taught by males and females - the researcher only had access to female 
students. These students attend a variety of colleges: Interior Design, Business Administration, Nursing and Health Sciences, and Engineering. The majority of the students in this study had not previously made intensive use of technology for studying or for other educational processes. This course was their first experience with online learning as a mandated part of their education.

Students were required to access the course material online, to engage in online discussion with classmates and professors in the discussion forum, to upload their assignments, to obtain their grades and professors' feedback online, to take their tests and exams online, and to communicate their feedback regarding every aspect of the course. Indeed, it is a requirement of these students' university programs that they access their courses via Blackboard and some may take blended courses combining traditional and online learning, which could be perceived as strange for some of them as it would be their first experience with online learning as a mandated part of their education. The course the students are taking with me is one of the early courses that requires them to use online learning. Students take online courses and they interact with their professors and student colleagues through online discussion forums. Many universities and colleges in Saudi Arabia have over the last five years established online communication forums to supplement and reinforce face-to-face teaching. But these particular institutions went further in mandating participation in online learning as a condition for graduation.

\section{Data Collection Procedure}

The researcher informed the students of the rationale for the study and provided them with an information letter and consent form. These asserted that there would be minimal risk associated with participating in the study because anonymity and privacy would be assured, and because the results of the study would not influence the students' course grades. Participants were made aware of the fact that they could withdraw from the data-collection process at any time. Students were given the consent form before the beginning of the data collection. They completed the questionnaire in the last week of classes, a process that required about 20-30 minutes. Anonymity was maintained by asking respondents not to write their names on the answer sheets and to submit them to the TA.

The researcher received and began to analyze the data only after the final examination and the submission of the course grades. Of the 100 participants who provided consent forms, 67 returned their answers. Follow-up interviews were conducted with a random selection of 20 participants. Informal discussions were held with each participant to provide enriched views on whether and to what extent there exists a reciprocal and correlative relationship between online learning and culture. The researcher made field notes of the discussions for later analysis. 
The analysis of the responses to the completed questionnaire began with an assessment of the descriptive data drawn from the students' feedback about how they perceive online learning and the culture of learning - whether the latter has been influenced by the advent of online learning. The analysis of the open items and field notes from the interviews (coding, constant comparison) was completed after reading and re-reading the short answers, using constant comparison. Representative responses, quotes, and field notes were selected to illustrate the themes and to serve as evidence for the assertions related to each research question.

The methodology used for this study had two main parts. The first involved an analysis of the discourse surrounding online integrative or blended education. This emphasized Saudi Arabia, a country where this is a new strategy in education as well as a new area of research. The second part of the study involved an analysis both of personal observations and of a survey created by the author and distributed among Saudi female first- and second-year undergraduate students from various classes of two major universities. All 67 of the participating students had experienced the integrative approach to online education through the requirement to use online learning as part of their university studies alongside traditional methods of education.

Prior to distribution, the survey was examined by an ethics committee and by professors at other institutions. The survey was undertaken in person and was data-driven, with a view to exploring how students' culture of learning had changed as a result of accessing and working with an integrative approach to online learning. The survey questions were supplemented with probes designed to steer students' thinking towards the relationship between learning culture and online education. The survey data were coded, themed, and analyzed according to their relevance to the research question. The results were read and re-read by the author to find similarities and differences in respondents' answers to the questions. As indicated below, there was a general consensus among the respondents that online education had positively influenced their learning experiences and outcomes.

\section{Results and Interpretation}

As explained above, Saudi university students come from a school culture that teaches them to rely on the teacher as the sole source of and conduit for knowledge. The strong hold that the traditional approach to education has on the minds of many students leads some of them to resist approaches that place them at the centre of learning - and this is especially the case when they have to engage in discussions as a precondition for learning. Online learning helps to address this tendency to resist by offering students a multitude of new opportunities to interact with classmates and professors in relation to their learning experiences. 
During the research study, the more reluctant students received encouragement from the course professors and this helped ensure that these students became active participants. Not long after the introduction of online learning, virtually all the students had become much more familiar with the methods of navigating internet sources and of interacting online with their professors and colleagues. Many students began to appreciate the positive effect of these new learning opportunities on their criticalthinking skills, cognitive skills, and oral and written communication skills, as well as on their general knowledge. Students' engagement in online communication cultivated new experiences and cultural interactions with their classmates and professors - experiences and interactions that not only helped to enhance written and oral communication skills but also to expand their understanding of the various issues discussed. Students also displayed more personal control over their learning. While the possible difficulties associated with online learning have already been outlined and need to be acknowledged by educators, the participants in this study did not single out any single major challenge that they faced.

One might argue that it would be a stretch to think that online learning can actually have an impact on a culture of learning in a relatively short time frame. This would surely take time, especially in a large society/country like Saudi Arabia with deep historical roots and entrenched traditions. Nevertheless, many Saudi students are acquiring a new culture of learning as a result of being introduced to online communication and web-based instruction. One of the core elements of this new culture of learning is the shift from unilateral communications from the professor to the students to a multilateral approach. Within this emerging approach, not only are communications between the professor and the students much more two-way but the students are also receiving opportunities to interact with each other in a classroom setting. Thus, thanks to online learning, Saudi students are being moved closer to the centre of learning.

\section{The Students' Feedback: Embedded Themes}

Some themes emerged from the data and in this section I discuss some of the points that repeatedly appeared in the students' feedback, in the professors' observations, and in the field notes. The emerging themes were mainly related to the changing learning culture in such areas as time-management skills and learning skills. From the data it appears that the students believe that online education gives them greater control over the learning process, including the ability to post their feedback and assignments online and to discuss points that interested them in the readings. This greater control is what is moving the students to the centre of the learning process and is therefore helping to change the learning culture.

When students were asked about how the integration of online communication affected and influenced their learning experience, the new interaction opportunities were frequently emphasized. As one student explained, 
It allows us to talk with the teacher directly and be able to be updated quicker... Any question about an assignment is usually assigned faster. It also makes the learning experience much more rewarding as we are able interact with the teacher and get feedback regarding small segments of the assignment.

Another student noted that "Online education helped us connect with other students and instructors easily and spontaneously." This point was echoed by the observation that "...online communication improves the process of learning. It enables students to be in touch with their colleagues and instructors other than saving their time when it's time for registrations and arranging schedules."

Yet another student commented that "Not being allowed to drive some days makes it hard to go to school, and using online education and Blackboard allows me to post my assignment on time without having to worry about getting to school for that purpose" [emphasis added]. Indeed, several respondents were very pleased with the fact that they could access their courses at any time and in any location.

A number of students narrated and indicated that online courses taught them to plan their time better and to rely on reading more in order to achieve better results. One said "when I go online I used to spend less time on reading and more on browsing various sites now I read much more when my instructor pose a question." Another said "online learning disciplined me to read much more than before" and another suggested "I award myself everytime I learn something new to read more and arrange my time better." These quotes reflected their ability to achieve long and short term goals and their selfdiscipline which were clear in their feedback of the interview questions. One of the short term goals was to overcome their disinterest in reading and they were able to read their books online, while the long term goal was implicit in these students' abilities to think outside the box and be at the center of learning rather than being empty vessels for their teachers.

Many students emphasized that the accessibility offered by online education is one of its greatest advantages. They explained how the use of online technology affects their learning experience in a variety of positive ways, including sharpening their thinking and broadening their horizons. As one student explained, "When you meet new people through online learning... you will learn from their experience and share your ideas and thoughts with them." Another student elaborated on the theme of expanded access to knowledge in stating that "It connects us with things that are not easily available in books... The concept of learning through books and going to the library is diminishing in face of online learning and online access to books and journals."

Many students were conscious of the cultural impact of online learning. According to one student, "Online education is starting to change the culture... It's now accepted that 
people study online and obtain their degrees and are able to continue with their education." Another observed that "...online education is changing the culture because we are now becoming increasingly dependent on the Internet and this is changing the culture of how we deal with one another." An especially perceptive student captured the reciprocity between online learning and culture: "Online education is expanding the culture which in turn influences education and how we view education... It is definitely changing our thinking in a positive way... Yet our culture is [also] influencing technology in that it is controlling it."

The vast majority of respondents agreed that this new approach to education ".. is changing the culture by providing people with learning material that comes from different sources that present different perspectives and aspects of that material." One student emphasized that online education is opening up brand new opportunities for her as a female:

I believe that culture is influencing online education because it is not simple for us girls to travel abroad for higher education in our society. Therefore I think that it motivates the female to turn to studying online due to our limited options.

A few students noted possible negative cultural consequences. One suggested that "People can get addicted to technology if they over use it." Another argued that online learning has a negative aspect because it reduces the frequency of face-to-face interactions. Some other students agreed that online communication has the disadvantage of sometimes sending a different message than that which is intended. However, for the majority of respondents, the major disadvantage of online learning is related to the unreliability of internet connections, largely resulting from censorship aimed at blocking access to sexual and political Web sites. Some respondents also indicated that it is sometimes impossible or extremely time-consuming to log onto the Internet.

\section{Discussion of Students' Learning Culture}

Culture is relevant to this research in that the researcher tested how Saudi female students' learning culture - through a representative group of participants - has been influenced by their online learning engagements. As discussed above, Saudi Arabia has a collectivist culture with high-context communications and minimal coding, though this was not specifically considered in the academic study in relation to online learning. The ways in which and the degrees of success with which female students interact, benefit, and grow with online learning need to be explored in greater depth over an extended time period. Although there were some limitations on access to online education as a result of poor or inadequate internet infrastructure as well as some technical difficulties, the study participants found it to be indispensable to have unlimited access to the 
Internet. They also argued that their introduction to online sources enabled them to gain experience with different ways of thinking, different styles of writing, and different approaches to improving their communication skills. They also learned to become more persistent as a result of the slowness of Saudi internet connections.

The students' participation in the online discussion forum included learning more about their own values, beliefs, and attitudes. Before joining the online integrated discussion forums, the students did not realize the diversity of perspectives among them. This is an example of how online forums can serve as a platform for promoting greater understanding of the diversity of cultures and opinions within the same society, as well as for fostering greater appreciation for how cultural differences impact learning. These outcomes of online forums, as well as the internalization of locus of control, help to build students' communications abilities in the workplace and elsewhere.

Based on personal observations of the students' online communications on discussion boards and of their abilities to engage with each other on a daily basis in regard to various aspects of what was discussed in the classroom, it was evident that their online discussions towards the end of the year displayed significant improvements in their skills in presenting their own perspectives. These constant observations were noted regularly so that they could be revisited during the data analysis, and notes were taken that made these observations and field notes into a form of transcript. These observations were made by two professors who were constantly engaging in the dialogue, both virtually and face to face. The observations and field notes significantly enriched the survey data from the participants.

Online programs encourage students to learn at their own pace and to interact at their own level. In one of the discussion forums, students were asked to respond to some assignments relating to ethical concerns and cultural issues associated with crosscultural communication. This discussion was enriching and may have challenged some of their existing deep-seated misunderstandings, judgments, and assumptions about different cultures. Another quality that students embraced is self-discipline, which is a necessary condition for success in a globalized world. Throughout their engagement with online learning, the students displayed their ability to work independently. This is particularly significant in that online education, in combination with traditional approaches to learning, enhances students' communication abilities, academic skills, and level of self-motivation - especially with respect to topics that are relevant to their lives. After a semester of using online education the students demonstrated better personal management skills, including the ability to set achievable goals. Online education therefore helped students to be more successful and to have higher levels of satisfaction after an initial full-year engagement. 


\section{Students' Empowerment}

The participants in this study showed a great deal of personal empowerment as a result of engaging in online learning. Students' empowerment was one of the main highlights of this study. As discussed above, Saudi students usually are not directly engaged in the learning process but, rather, are educated through lectures alone. According to this traditional approach, students are required to abstain from discussions or other kinds of direct participation in learning and, in consequence, they do not contest, negotiate, discover, or share their understandings. However, after employing the blended approach, which included participating in online discussions, most of the students in the research sample demonstrated a keen interest in moving beyond the rote-learning tradition. In other words, the students demonstrated a greater appetite and aptitude for interactive learning - for an educational approach that is premised on bilateral and multilateral communications as opposed to the traditional unilateral approach. A new willingness to engage in critical thinking and self-directed learning was also one of the most notable effects of the implementation of online education. Unlike under the old model of instruction, students who engage in online learning are more likely to display their autonomous identity - an identity that emerges through the acquisition of skills that serve as the scaffolding for the acquisition of knowledge. "Scaffolding" refers to the structure of skills that enables students to reach new levels of educational and personal development.

\section{Solutions and Recommendations}

Students must be able to understand the protocols and guidelines for using online communication before joining online communities. These protocols concern the ethical standards that are necessary for students to become responsible users of online resources. Some of these ethical standards include respecting privacy, maintaining security, and avoiding plagiarism and academic dishonesty. Yet, despite such concerns, it appears from this research study that few concrete measures are being undertaken to address them. Unfortunately, in Saudi Arabia the centralized server has in many cases proved to be detrimental to learning, as it is often used to prevent or restrict access to important web sources because they touch on controversial issues of a political, sexual, or religious nature even if these are related to educational fields. Centralization helps to standardize procedures and practices, but it can also be used to limit students' access to many valuable internet resources. Thinking should not be restricted or censored, regardless of the subject. This restriction should be studied and discussed further, with a view to its eventual reform.

Gender segregation is pervasive in Saudi Arabia. All education is completely separated from grade one up to and including higher education, with the only exception being the final years of medical school, where male students are seated in rows in front of female students. This study focused solely on female students' responses to and participation in online learning. Future studies would benefit from the addition of input and analysis 
from male students. A comparison between male and female responses would allow for critical analysis of the discourse that surrounds male and female education.

Another recommendation is to enhance students' level of computer literacy in order to boost their confidence in participating in online integrated courses. In order to overcome the various challenges associated with online culture, students and instructors must be vigilant about students' disregard for or lack of knowledge about the privacy protocol. This protocol includes the requirement for students to respect both professors and classmates and to avoid disclosing personal information to each other and on the Internet except where absolutely necessary. Clear instructions must be provided. It cannot be expected that students who are encountering a progressive education philosophy for the first time and who are the products of the traditional approach to learning would know what should and should not be done to protect their privacy with a view to allowing them to reach their full potential in online discussions. Another protocol applies when students use other people's ideas in posts; specifically, they need to learn when and how to give credit to the author or the creator.

Learning styles differ widely among individuals (Kolb, 1984) and building an awareness of this is important in online-learning processes. In saying this, it must be acknowledged that students' ability to successfully use online education is also related to the fact that "distance education is inherently accommodating of a variety of learning styles" (Dille \& Mezack, 1991 as cited in Dabbagh, 2007, p. 218). With various media such as video, audio materials, and the delivery of text via the Internet, students who tend towards visual, spatial, auditory, or text-oriented learning styles are being accommodated through online learning.

\section{Future Research Directions}

The trend towards employing online learning in the vast majority of post-secondary academic programs worldwide is having a significant impact on learning cultures. Yet, despite this widespread integration of online learning with traditional education, there remains little research into the factors that make online learning a significant part of undergraduate students' learning experiences. The observation put forward by Bourne et al. (1997) a decade and a half ago that "The way learners acquire knowledge in on-line settings has not been extensively studied" (p. 39) still largely holds true. Newton, Hase, and Ellis (2002) suggested:

The widespread rhetoric of promises for more flexible access to training and the subsequent rapid adoption of these goals by government, educational institutions and industries have not been accompanied by an understanding of the factors and processes that contribute to effective implementation of online learning. (p. 157) 
Some of the questions that remain unexplored more than 10 years later relate to cultural values and the ways in which they are influenced by online learning and open online communication. Are those higher-education institutions that are offering courses to diverse learners around the world paying enough attention to differences between cultures? Should online courses be designed to reflect the culture of the audience? How is access to sources of online learning influencing learners and their respective cultures? What cultural challenges do instructors encounter when planning e-learning courses? To what extent is e-learning adaptable to non-Western students' needs and cultures?

More research is needed to explore the importance of asynchronous group discussion in the online context. Studies by Henri (1992) and Garrison (1992) have experimented with the ways in which computer asynchronous classes are exhibited and affect students' learning, yet research is needed to examine the difficulties that are specific to online learning culture. Relevant online learning strategies should be implemented to help students become more creative in using their various skills.

Future research should also examine the ways in which online education is affecting teachers and instructors - specifically whether it is affecting the teaching culture, the course management, the teaching strategies, or some combination thereof. Detailed qualitative studies could provide great insight into blended online courses. A possible project might be to identify students across various cultures who are taking the same online course and to interview them regarding the ways in which and the extent to which their cultural identity has been thereby influenced. Online communication is a tool for crossing geographical boundaries and thus it could be used to connect cultures and build bridges of understanding to a greater extent than has hitherto been possible.

\section{Conclusion}

This paper demonstrates that online learners' culture of learning is influenced by online education and vice versa. It also provides ideas on how students' learning can be enhanced in the process of connecting to one another and to their professors. It furthermore provides insight into the ways in which the introduction of online learning can complement traditional teaching approaches and, in turn, positively impact students' learning cultures. The evidence shows that students' cultural background influences their perception and performance in online learning environments in the sense that some students from some cultures require more help than some students from other cultures in order to become independent learners (Almutairi, 2008).

This study analyzed student-student and student-instructor interactions reflecting students' engagement in and benefits derived from open and online learning. Students revealed how their engagement in online discussion improved their critical-thinking skills and allowed them to think deeply about various subjects in ways that would not be possible if it were not for online learning. Students' engagement in online learning helps 
them to develop greater planning and time-management skills as well as greater selfdiscipline. Students in the study displayed an improvement in their abilities to set shortand long-term goals. These students' excitement for and involvement in many of the aspects of the technology available to them made online education an outstanding vehicle for the improvement of their skills. Traditional learning approaches are still dominant in most Saudi classrooms. Nevertheless, online education is in the process of being introduced and many universities are employing blended learning strategies that are constructing new learning realities for students. Students' learning culture is clearly being positively influenced by online education - an approach that enables them to actively participate in discussions, to engage in self-directed learning, and to construct their learning by drawing on and creating their own experiences. Thanks to online learning, the traditional unilateral approach to education is being supplemented and even changed to reflect a more multilateral ethos. 


\section{References}

Alenezi, A. (2012). Faculty members' perception of elearning in higher education in the Kingdom of Saudi Arabia (KSA) (Unpublished doctoral dissertation). Texas Tech University, Texas.

Al-Khalifa, S. H. (2009, 2012). The state of distance education in Saudi Arabia. Retrieved from http:// elearnmag.acm.org/archive.cfm?aid=1642193

Almutairi, n. H. (2008). The influence of educational and sociocultural factors on the learning styles and strategies of female students in Saudi Arabia. University of Leicester, Leicester.

Al Seghayer, K. (2013). The impact of four reading motivational constructs on motivating EFL learners to read online texts in English. International J ournal of Computer-Assisted Language Learning and Teaching (IJ CALLT), 3(2), 26.

Altmann, H., \&Arambasich, L. (1982). A study of locus of control with adult students. Canadian J ournal of Counselling and Psychotherapy, 16(2), 97-101.

Bates, T. (2009). A personal view of e-learning in Saudi Arabia .Retrieved from http:// www.tonybates.ca/2009/11/05/a-personal-view-of-e-learning-in-saudiarabia/

Benbunan-Fich, R., \& Hiltz, S. R. (1999). Educational applications of CMCS: Solving case studies through asynchronous learning networks. J ournal of ComputerMediated Communication, 4(3). Retrieved from http:// www.ascusc.org/jcmc/vo14/issue3/ benbunan-fich.html

Bourne, J ., McMaster, E., Rieger, J ., \& Campbell, J . (1997). Paradigms for on-line learning: A case study in the design and implementation of an asynchronous learning networks (ALN) course. J ALN, 1(2).

Cameron, H., \& Limberger, J . (2004). Online learning: Cross cultural development in time poor environments. J ournal of European Industrial Training, 28(5), 429439.

Cooper, E. (1990). An analysis of student retention at Snead State J unior College. Nova University (ERIC Document Reproduction Service No. 329 298).

Corvette, B. (2007). Conflict management: A practical guide to developing negotiation strategies. New York: Pearson.

Dabbagh, N. (2007). The online learner: Characteristics and pedagogical implications . Contemporary Issues in Technology and Teacher Education, 7(3), 217-226. 
Duignan, G. (2012). Teaching international teachers: How Saudi Arabian teachers experience learning about teaching during a New Zealand professional development course (Unpublished dissertation). University of Canterbury, Canterbury.

Garrison, D. R. (1992). Critical thinking and self-directed learning in adult education: An analysis of responsibility and control issues. Adult Education Quarterly, 42(3), 136-148.

Gunawardena, C.N., Wilson, P.L., \&Nolla, A.C. (2003). Culture and online education. In M.G. Moore \&W.G. Anderson (Eds.), Handbook of distance education (pp. 753-775). Mahwah, NJ : Lawrence Erlbaum Associates

Gupta, S. (2010). A quick guide to cultural competency. Retrieved from http:// www.guptaconsulting.com

Hara, N., \& Kling, R. (2009). Students' distress with a web-based distance education course: An ethnographic study of participants' experiences. Information, Communication and Society, 3(4), 557-579.

Henri, F. (1992). Computer conferencing and content analysis. In A. R. Kaye (Eds.), Collaborative learning through computer conferencing: The Najaden papers (pp. 115 - 136). New York: Springer.

Hill, J . R. (2002). Strategies and techniques for community building in Web based learning environments. J ournal of Computing in Higher Education, 14(1), 67- 86.

Hofmann, D. W. (2002). Internet-based distance learning in higher education. Tech Directions, 62(1), 28- 32

Hofstede, G., Hofstede, G. J ., \& Minkov, M. (2010). Cultures and organizations: Software of the mind ( $3^{\text {rd }}$ ed.). United States of America: McGraw-Hill.

Kim, K., Liu, S., \& Bonk, C. (2005). Online MBA students' perceptions of online learning: Benefits, challenges, and suggestions. Internet and Higher Education, 8, 33-35.

Kolb, D. A. (1984). Experiential learning: Experience as the source of learning and development. NewJ ersey: PrenticeHall.

McPeck, J . (1981). Critical thinking and education. Oxford: M. Robertson.

Mirza, A. A. (n.d.). Is e-learning finally gaining legitimacy in Saudi Arabia? Retrieved from faculty.ksu.edu.sa/ .../Is\%20elearning\%20finally\%20gaining\%20legitimacy\%20in\%20Saudi\%20 
Moon, J . (1999). Reflection in learning and professional development: Theory and practice. London: Kogan Page \& Sterling.

Newton, D., Hase, S., \& Ellis, A. (2002). Effective implementation of online learning: A case study of the Queensland mining industry. J ournal of Workplace Learning, $14(4), 156-165$.

Ohara, M. (2004). Maximazing e-learning Roi: Identifying successful online learners . Allied Academies International Conference, 8(1), 49-54.

Owston, R.D. (1997). The World Wide Web: A technology to enhance teaching and learning? Educational Researcher, 26(2), 27 - 33.

Pacey, A., (1983). The culture of technology. Cambridge, MA: MIT Press.

Pattison, S. (2003). Cultural diversity: Mapping the experiences of students on an international counsellor training programme. Counseling and Psychotherapy Research, 3(2), 107-113.

Piaget, J . (2000). "Commentary on Vygotsky". New Ideas in Psychology, 18, 241- 59.

Renner, W. (2006). E-learning 2.0: New frontier for students empowerment. Paper presented at the Edu-Com 2006: Engagement and Empowerment, Thailand.

Rourke, J .R. (2001). Online learning: Fad or fate? Principal Leadership, 1(9), 8 - 14

Song, L., Singleton, E. S., Hill, J . R., \& Koh, M. H. (2004). Improving online learning: Student perceptions of useful and challenging characteristics. Internet and Higher Education, 7, 59- 70.

Tapanes, M., Glenn, G., Smith, B., J ames, A., \&White, B. (2009). Cultural diversity in online learning: A study of the perceived effects of dissonance in levels of individualism/ collectivism and tolerance of ambiguity. Internet and Higher Education, 12, 26-34.

Vygotsky L. S. (1992). Ape, primitive man and child: Essays in the history of behavior. New York: Harvester Wheatsheaf;.

Schrum, L. (2000). Online learning in the academy: The conundrum that may divide us. Technos, 9(3), 34-36

Wang, C., \& Reeves, T. C. (2006). The meaning of culture in online education: Implications for teaching, learning, and design. In A. Edmundson (Ed.), Globalized e-learning cultural challenges (pp. 1-17). Hershey, Pennsylvania: Idea Group Inc. 


\section{APPENDIX A}

\section{Letter of Information}

\section{Informed Consent Letter}

Online Learning

Dear Participant:

My name is Dr. Amani Hamdan, Assistant Professor. This is an invitation for you to participate in our research in which I seek to explore your learning experience using online learning programs asynchronously and/or synchronous. The data from this project will be used for scholarly presentations and publications.

In this study, written surveys will be the primary methods for gathering data. If you agree to participate, you will provide short answers in the survey.

Your identity will be maintained confidential in the project and any write up. The original or raw data will be stored under lock and key, and only I as sole researchers will have access to the raw data. If you choose to provide your written reflections this will be kept confidential, all the data will be kept two years after the research is complete, after which the raw data will be destroyed.

Your participation is voluntary and you may withdraw from the study or refuse to answer any question at any time. As a participant in the study, you will at no time be judged, evaluated or be at risk of harm. Neither your name nor the institution's will be revealed in any written reports. Once I receive your permission, we will follow up to arrange a suitable time for the interview.

Sincerely, 


\section{Appendix B}

\section{PART One:}

Interview Questions

Name:

Institution:

Number of years using online learning:

1) How integrating online communication affecting and influencing your learning experience? (short answers) 6 line minimum

2) How online education is changing the culture or culture influencing online education?

3) How online education is changing you and how is online education influencing you?

4) What do you perceive your teacher role in online learning? What about your role?

5) How frequent do you use online for educational purposes?

Part Two:

6) How frequent do you use Web Ct or Blackboard to access your courses online?
a) 1-10 hours
b) 10-20 hours
c) More than 20 hours
d) More than 40 hours

7) How frequent do you engage in online discussion on Web Ct or Blackboard?
a) 1-10 hours
b) 10-20 hours
c) More than 20 hours
d) More than 40 hours 
8) How many courses have you taken online
a. 1-3
b. $3-5$
c. $7-9$
d. More than 10

9) How frequent do you use online educational activity per week?
e) 1-10 hours
f) $10-20$ hours
g) More than 20 hours
h) More than 40 hours

10) What web pages do you use most?
a) Google
b) Ask me.com
c) Wikipedia. com
d) Others (specify)

11) Do you benefit from learning online? How?

12) Do you feel safe to state your opinion in an online learning course more than howyou feel in a traditional classroom?

13) Are you more motivated to engage in online discussion than in a traditional classroom?

\section{Athabasca University $\mathbf{a}$}

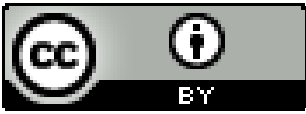

